\title{
Brief Communication: Occurrence of an Eighth Cusp on Primary Second Mandibular Molars of a Contemporary Argentinean Child
}

\author{
Carlos David Rodríguez Florez ${ }^{1^{*}}$, Gabriel Mario Fonseca², and Maria Teresa de Villalba ${ }^{3}$ \\ ${ }^{1}$ Cátedra de Antropología Biológica y Cultural, Facultad de Ciencias Exactas, Físicas y Naturales, \\ ${ }^{2}$ Cátedra de Anatomía Patológica B, Facultad de Odontología, and ${ }^{3}$ Cátedra de Ortodoncia, Facultad de \\ Odontología - Universidad Nacional de Córdoba, Argentina.
}

ABSTRACT: The presence and asymmetry of an eighth cusp observed on the primary second mandibular molars of an Argentinean boy is described. Dental Anthropology 2006;19(3):83-85.
Dental morphology trait expressions have been used in anthropology and forensic sciences for determination of biological and geographical affiliations. Variations in morphology of crowns may be manifest in the primary and/or permanent dentitions. Dental variation is heritable, is caused by multiple genes, and is little influenced by environmental factors. Traditionally, three, four, five, six or seven cusps, specifically the protoconid, metaconid, hypoconid, rntoconid, hypoconulid, entoconulid and metaconulid, have been reported in morphological descriptions of lower molars for various human groups (Axelsson and Kirverskari, 1979; DeVoto and Perroto, 1972; Hanihara, 1967; Harris and Bailit, 1980; Morris, 1965; Sciulli, 1977; Schroeder et al., 1983; Scott and Turner 1997; Suzuki and Sakai, 1973). This brief communication reports on the presence and asymmetry of a possible eighth cusp on mandibular primary second molars of a contemporary Argentinean boy.

\section{MATERIALS AND METHODS}

The teeth of a racially mixed boy five years of age from Cordoba City, Argentina, were examined in situ and on a plaster cast. An unusually shaped accessory occlusal cusp was observed on both the left and right mandibular primary second molars. Size of this eighth cusp was measured with sliding calipers. This case report is part of an anthropological study carried out on material provided by the Departamento de Ortodoncia, Facultad de Odontología, Universidad Nacional de Cordoba, Argentina.

\section{RESULTS}

Figures 1 and 2 illustrate the presence and bilateral asymmetry observed on mandibular primary second molars. A small additional cusp occurs between hypoconulid and entoconulid cusps. The anomalous cusp is larger on the right molar (diameter: $0.245 \mathrm{~mm}$ ) than the left (diameter: $0.165 \mathrm{~mm}$ ).

\section{DISCUSSION}

This accessory, eighth cusp has been not reported previously. This rare variant on anomalous lower primary molars provides an interesting record of eighth cusp in human dental morphology. Bilateral presence and asymmetrical appearance of the eighth cusp suggest a possible factor of heritability in the expression of this infrequently human molar form. Brabant suggests that primary second mandibular molars with five cusps are most common. Six cusps are less frequent ( $2 \%$ to $30 \%$ ), and the seven-cusp molar - with a cusp of Jørgensen (metaconulid) - is found in less than 10\% of cases (Brabant, 1967). Kallay's (1966) classification

Grant Sponsor: Facultad de Odontología, Universidad Nacional de Córdoba, Argentina.

${ }^{*}$ Correspondence to: Carlos David Rodríguez Florez, Cátedra de Antropología Biológica y Cultural, Facultad de Ciencias Exactas, Físicas y Naturales - Universidad Nacional de Córdoba, Argentina.

E-mail: david@syllabapress.com 

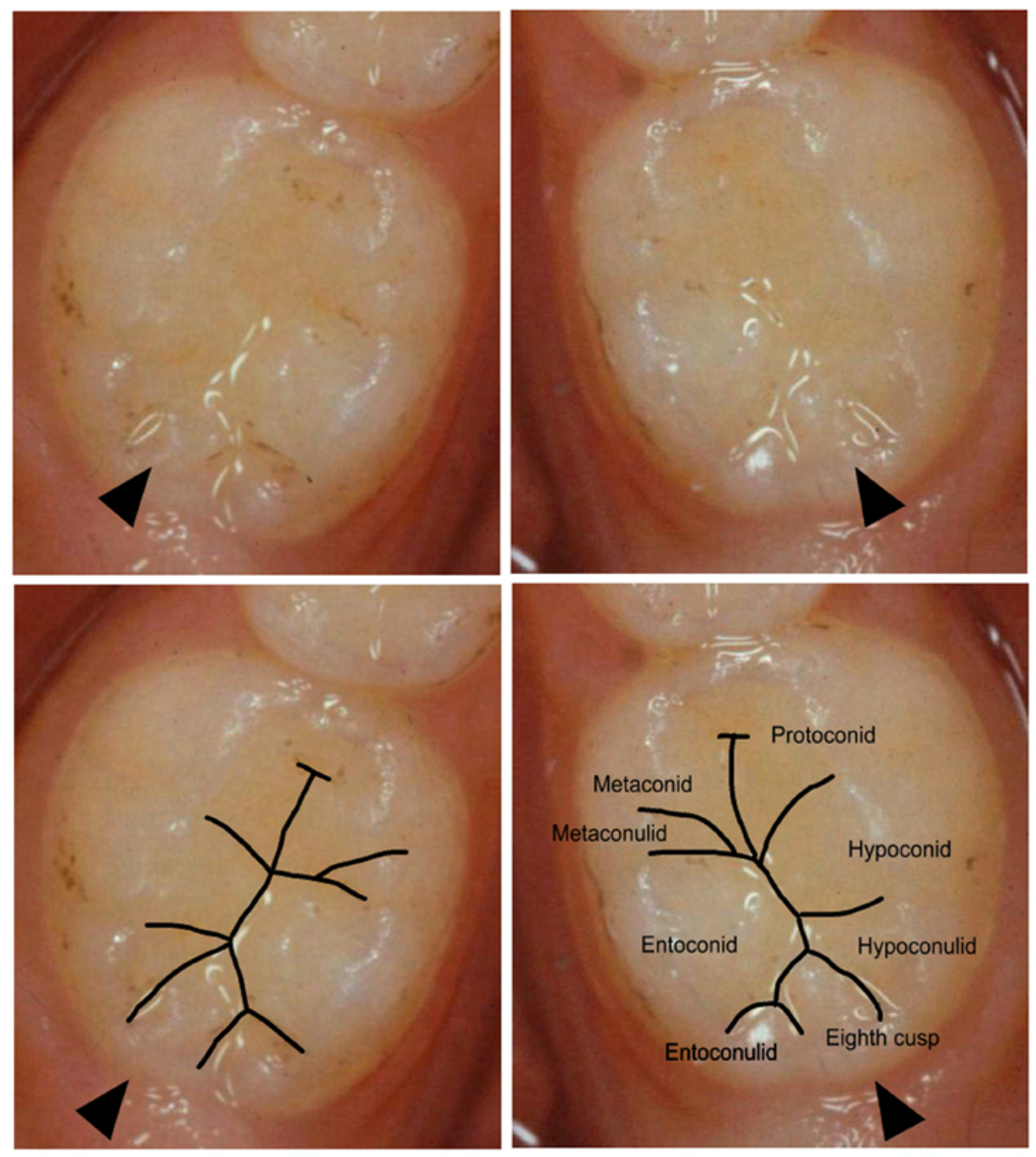

Left Lower Molar

Right Lower Molar

Fig. 1. Occlusal view of case (in situ).

could be used to label this eighth cusp, perhaps the Protuberantio apulparis sited in the distal occlusal area of primary second lower molars. As mentioned by Brothwell (1967), the phenomenon of increasing world contact, immigration, and interbreeding between previously more isolated communities can produce new forms that enrich the variation observed in the human dentition.

\section{LITERATURE CITED}

Axelsson G, Kirveskari P. 1979. Sixth and seventh cusp on lower molar teeth of Icelanders. Am J Phys Anthropol 51:79-82.

Brabant H. 1967. Comparison of the characteristics and anomalies of the deciduous and the permanent dentition. J Dent Res 46:897-902.

Brothwell DR. 1967. Some problems and objectives related to the study of dental variation in human populations. J Dent Res 46:938-941.

DeVoto FCH, Perroto BM. 1972. Groove pattern and cusp number of mandibular molars from Tastilian Indians. J Dent Res 51:205.

Hanihara K. 1967. Racial characteristics in the dentition. J Dent Res 46:923-926.

Harris EF, Bailit HL. 1980. The metaconule: a morphologic and familial analysis of a molar cusp in humans. Am J Phys Anthropol 53:349-358.

Kallay J. 1966. Extra cusp formation in the human dentition. J Dent Res 45:1381-1394.

Morris DH. 1965. The anthropological utility of dental morphology. Ph.D. dissertation, Department of Anthropology, University of Arizona. Tucson, AZ.

Sciulli PW. 1977. A descriptive and comparative study of the deciduous dentition of prehistoric Ohio Valley Amerindians. Am J Phys Anthropol 46:71-80. 


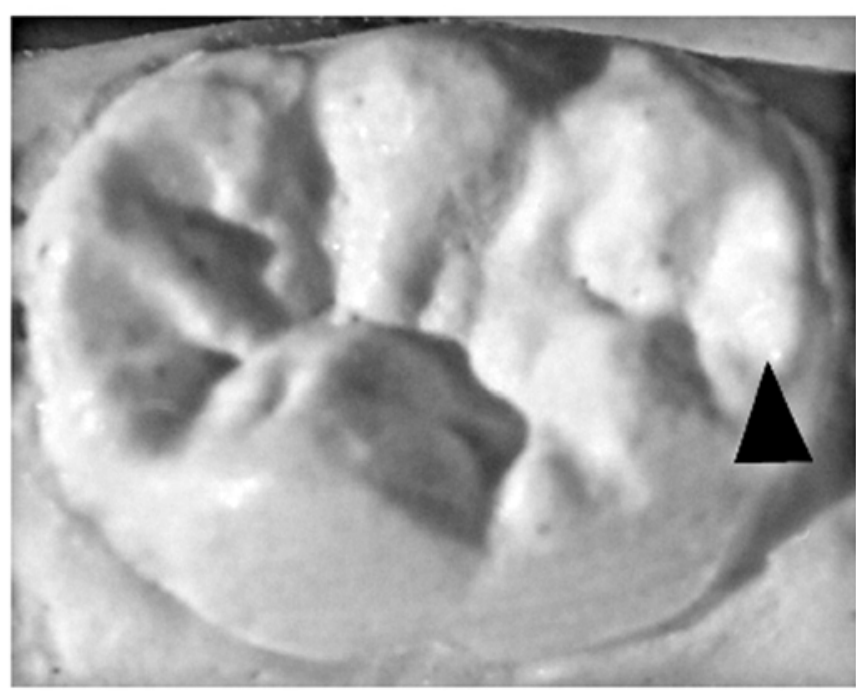

Left Lower Molar

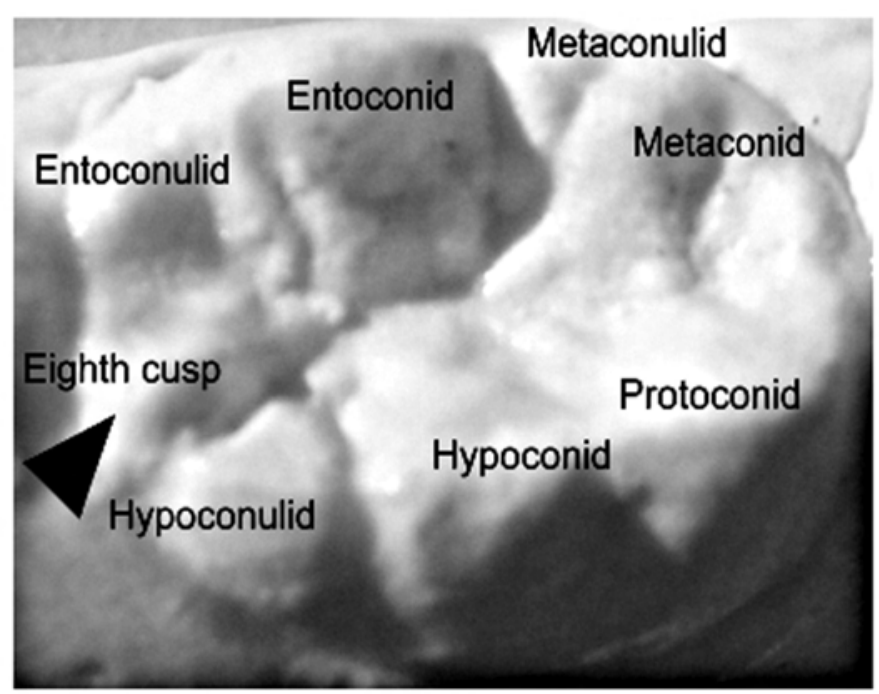

Right Lower Molar

Fig. 2. Occlusal view of the mandibular second molars as seen on the plaster cast.

Schroeder K, Zacherl W, Paulson R, Gaston P, Sciulli PW. 1983. Cusp tip abnormalities in the deciduous and permanent dentitions. J Dent Res 62:224.

Scott GR, Turner II CG. 1997. The anthropology of modern human teeth. Cambridge: Cambridge University Press.

Suzuki M, Sakai T. 1973. Occlusal surface pattern of the lower molars and the second deciduous molar among the living Polynesians. Am J Phys Anthropol 39:305-315. 